\title{
Process for obtaining synthetic foam with aluminum matrix Al-5052 by method of tixoinfiltration
}

\begin{abstract}
The metallic foams have lower density, and important physical, mechanical, thermal and acoustic properties, has been highlighted in its use in innovative technologies. As a subgroup of the class of metallic foams, the syntactic metallic foams which consists of the addition of hollow ceramic balloons in a metallic matrix in aluminum Al-5052 by process of tixoinfiltration. The microstructure was studied by optical and electron microscopy extended by energy-dispersive X-ray spectrometry, while the basic mechanical properties were mapped by standardized compression tests. Therefore, a syntactic foam design was developed in this work, where we obtained a $30 \%$ reduction in density and a reasonable increase in hardness due to the homogeneous dispersion of the ceramic balloons.
\end{abstract}

Keywords: tixoinfiltration, aluminum Al-5052, ceramic balloons, syntactic metallic foams
Volume 7 Issue I - 2020

\author{
João Roberto Sartori Moreno, Rafael \\ Claudiano de Moraes, João Paulo de Oliveira \\ Paschoal, Rodrigo Henrique Lopes \\ Department of Mechanical Engineering at UTFPR - Federal \\ Technological University of Paraná, Brazil
}

Correspondence: João Roberto Sartori Moreno, Department of Mechanical Engineering at UTFPR - Federal Technological University of Paraná Campus Cornelio Procópio - 86300-000, Brazil,Email joaosartori@utfpredu.br

Received: December 16 2019| Published: January 20, 2020
Abbreviations: EEA, atomic emission spectrometry equipment; CED, calorimetry thermal analysis; SEM, scanning electron microscopy

\section{Introduction}

Throughout history society has been in need of a continuous technological development as a way of meeting the challenges that human evolution itself imposes was explored by Banhart J. ${ }^{1}$ One of the main areas related to this advance is the design and improvement of materials and alloys, since the emergence of new technologies and applications results in the need for improved material characteristics such as increased mechanical strength, high temperature resistance, weight reduction, better resistance to harsh environments, among other properties. As a result of these factors, research centers have devoted time and resources to developing new engineering materials. Metal foams are a new class of materials that have emerged due to these needs, having as characteristics a material with lower density, and innovative physical, mechanical, thermal, electrical and acoustic properties. A subgroup of the class of metallic foams is the syntactic metallic foams as reported by Gupta et al., ${ }^{2}$ which consists in the addition of hollow ceramic particles in a metallic matrix. In this work a design of syntactic metallic foam is developed, aiming at reducing density and improving mechanical properties associated with structural applications. It has been produced by adding ceramic micro-balloons to an aluminum matrix by process of tixoinfiltration. The matrix material is usually an aluminum alloy, which has low cost and density, but currently other matrices have been studied, such as zinc, iron and others according Luong et al. ${ }^{3}$

\section{Metallic alloy used}

The alloy used in the metal matrix was the commercial aluminum alloy Al 5052, which has magnesium as its main alloying element. The main factors that led to their choice were their wide commercial use, their excellent corrosion resistance in the marine atmosphere, and their potential reliability, which will be further explained below. The values used as reference for alloy characteristics and properties are derived from the Metals Handbook. ${ }^{4}$ The material used had its chemical composition determined (Table 1) by the atomic emission spectrometry equipment (EEA).

Table I Chemical Composition of Al5052 Alloy

\begin{tabular}{lllllllllll}
\hline Element & $\mathbf{S i}$ & $\mathrm{Fe}$ & $\mathrm{Cu}$ & $\mathbf{M n}$ & $\mathbf{M g}$ & $\mathrm{Cr}$ & $\mathbf{N i}$ & $\mathbf{Z n}$ & $\mathrm{Ti}$ & $\mathrm{Al}$ \\
\hline$\% w t$ & 0.12 & 0.309 & 0.0067 & 0.028 & 1.882 & 0.171 & 0.0041 & 0.026 & 0.021 & Balance \\
\hline
\end{tabular}

The possibility of processing semi-solid metal alloys depends on their suitability, that is, on the ability to control the relationship between the liquid and solid fractions of the thixotropic mixture, as well as the range of solidification of the alloy and the sensitivity of the liquid fraction with the temperature according Manonukul et $a .^{5}$ In this work we used the differential exploratory calorimetry thermal analysis (CED), Figure 1, in which the black line represents the heating and cooling curve during the test, which was performed at a thermal variation rate of $5^{\circ} \mathrm{C} / \mathrm{min}$, and the blue curve represents the change in energy over time. The determination of the thermal parameters of the alloy is made from the energy flow curve by the temperature, finding the inflection points in the curves of their first and second order derivatives.
The found values of temperature $\mathrm{T}_{\text {solidus }}=607^{\circ} \mathrm{C}$ and $\mathrm{T}_{\text {liquidus }}=649^{\circ} \mathrm{C}$ are consistent when compared to the theoretical reference values in the Metals Handbook $\left(\mathrm{T}_{\text {solidus }}=607^{\circ} \mathrm{C}\right.$ and $\left.\mathrm{T}_{\text {liquidus }}=649^{\circ} \mathrm{C}\right)$. From empirical tests, liquid fractions between $75 \%$ and $80 \%$ of the thixotropic mixture result in better process conditions. Therefore the temperature of $644^{\circ} \mathrm{C}$ was selected as the working temperature because it had $78.14 \%$ of liquid fraction in this condition. Several components have been investigated to compose metallic matrices, but hollow ceramic spheres have been the most effective. So much so that Santa Maria et al. ${ }^{6}$ and Ferguson et al..$^{7}$ produced $\mathrm{Al}_{2} \mathrm{O}_{3}$ hollow sphere reinforced syntactic aluminum matrix foams and determined that the foam strength is a function of the charge intensity to particle size ratio. 


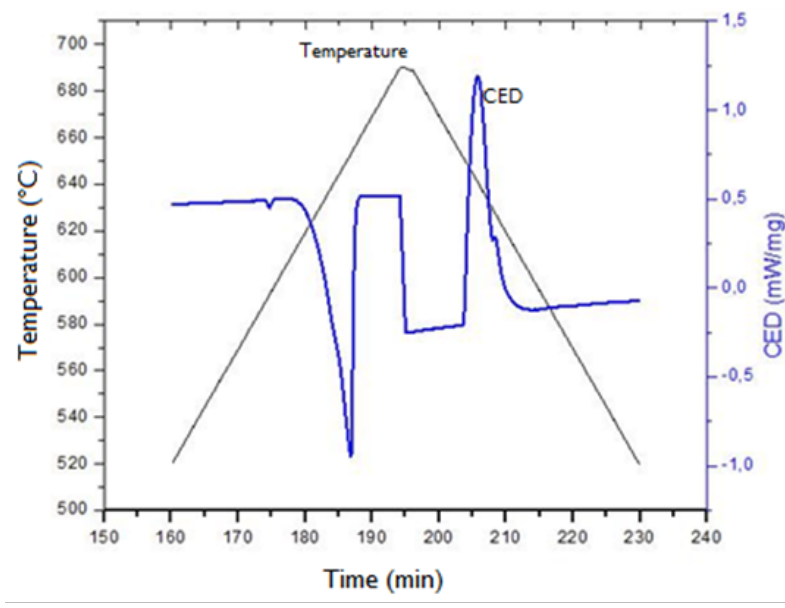

Figure I Differential exploratory calorimetry test curve of the AI 5052 alloy containing the variation of energy flow (blue color curve) in the sample during heating and cooling, and temperature (black color curve), both as a function of time.

\section{Ceramic balloons}

The ceramic micro-balloons used come from the coal combustion by-product, known as Fly Ash, because they have a hollow structure and a density between 0.6 and $0.8 \mathrm{~g} / \mathrm{cm}^{3}$. They are ideal to be applied in the production of metallic foams syntactic. The balloons used in the work were separated by sieving and the different acquired portions were analyzed by scanning electron microscopy (SEM), Figure 2, for the quality and dimensions of the balloons as reported Orbulov. ${ }^{8}$ The 100 grit size was chosen because it presented better quality and size of the balloons, having average dimensions A (balloon length) and B (width) of $266.185 \mu \mathrm{m}$ and $197.745 \mu \mathrm{m}$, with a wall thickness of $2.5 \mu \mathrm{m}$. obtained from a simple mean statistical analysis of the values measured by the SEM test.

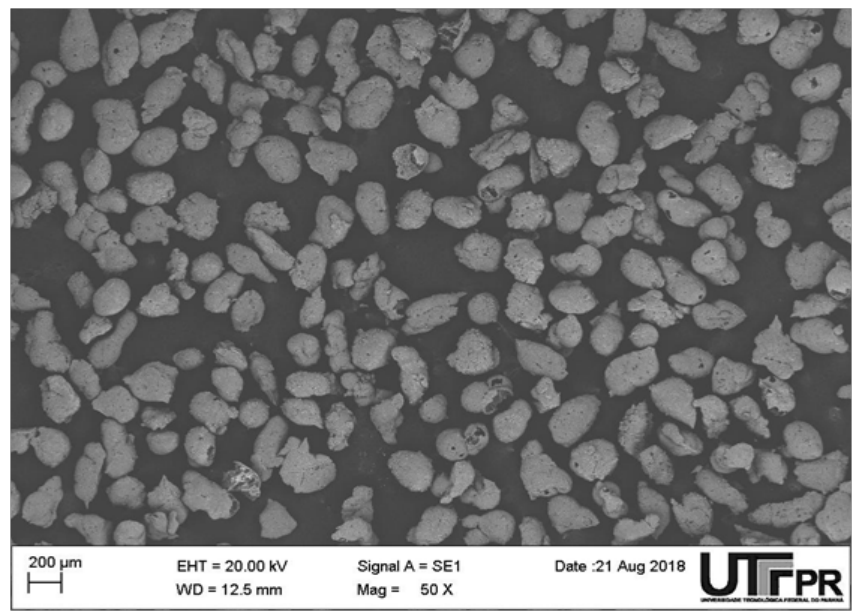

Figure 2 SEM of Fly Ash substrate balloons.

\section{Tixoinfiltration process}

In a steel mold machined for the procedure, two aluminum alloy discs were positioned, and a $5 \%$ by weight portion, relative to the aluminum portion, of Fly Ash balloons between these discs. The assembly was baked at a heating rate of $5^{\circ} \mathrm{C} / \mathrm{min}$ until it reached a working temperature of $644^{\circ} \mathrm{C}$, which was measured by a K-type thermocouple in direct contact with the upper aluminum alloy disc. After reaching the working temperature the assembly underwent an infiltration process using a hydraulic press, and the infiltration force was limited to $5 \mathrm{kN}$ to prevent balloon collapse during the process. The product obtained in this process is shown in Figure 3, and the excess aluminum present is subsequently removed by the machining process.

Composite blocks should be produced and characterized in accordance with the current standard for compression of cellular materials to ensure full comparability as reported by Szlancsik et al. ${ }^{9}$

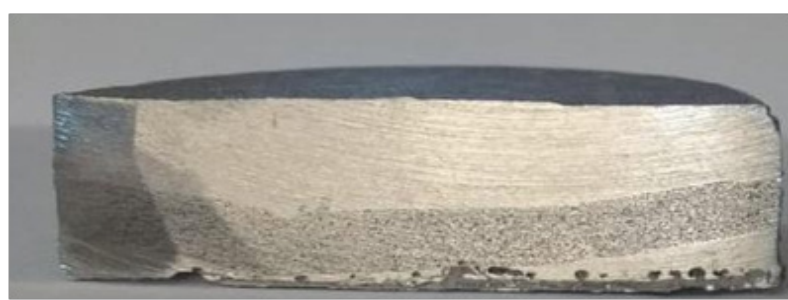

Figure 3 Sandwich panel with syntactic foam interior obtained by the thixoforming process at infiltration temperatures above $644^{\circ} \mathrm{C}$.

\section{Results and discussions}

It was possible to obtain an aluminum syntactic foam by tixoinfiltration process, as can be observed by the microscopy of Figure 4, from the analysis of the same it was possible to observe a homogeneous distribution of the balloons in the metallic matrix and their total anchorage, showing no defects in the interface of the ceramic balloon with the matrix according Orbulov et al. ${ }^{10}$ By analyzing the images using Image $\mathrm{J}$ software, using the binarization tool it was possible to determine the average porosity and to calculate the approximate value of the obtained density $45 \%$ and $1.8 \mathrm{~g} / \mathrm{cm}^{3}$.

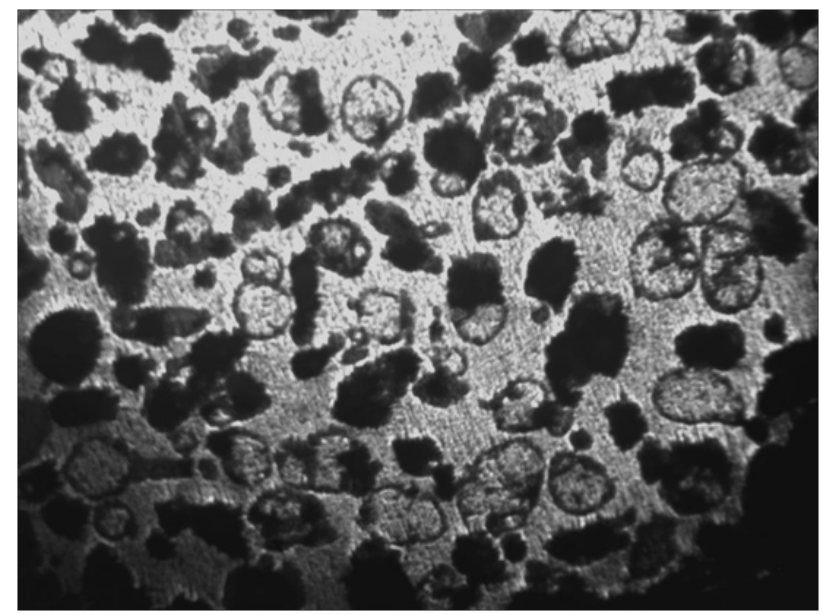

Figure 4 Optical microscopy of metallic foam with 5 times magnification.

For mechanical property analysis the Vickers hardness test was performed, the results are presented in Table 2 . The test was performed following the ASTM standard E $384^{11}$ with 100 gf of preload, with the results obtained it can be seen that the material had a Reduction of its hardness when subjected only to the tixoinfiltration process since recrystallization of the grains that were deformed due to the 
lamination process in the production of the base material, but in the foam region, the hardness in the metallic matrix increased.

Table 2 Vickers hardness test values measured

\begin{tabular}{llll}
\hline & Measure I & Measure 2 & Measure 3 \\
\hline Material laminate & $63 \mathrm{HV}_{100}$ & $65 \mathrm{HV}_{100}$ & $67 \mathrm{HV}_{100}$ \\
Material tixconformad & $60 \mathrm{HV}_{100}$ & $60 \mathrm{HV}_{100}$ & $60 \mathrm{HV}_{100}$ \\
Foam metalic & $70 \mathrm{HV}_{100}$ & $75 \mathrm{HV}_{100}$ & $75 \mathrm{HV}_{100}$ \\
\hline
\end{tabular}

\section{Conclusions}

The results obtained for the production of metallic foam were satisfactory, since it was possible to determine the optimal parameters for the production of a foam with homogeneous distribution of the particles, which generated a reduction of approximately $30 \%$ of density with respect to aluminum matrix. Also, it was possible to observe a 10 to $13 \%$ increase in microhardness in relation to the laminated and thixconformed material.

\section{Acknowledgements}

We are grateful to the Araucaria Foundation - PR and Federal Technological University of Paraná, which awarded a scientific initiation scholarship to the student Rafael Claudiano de Moraes.

\section{Conflicts of interest}

No conflicts to declare.

\section{Funding}

None.

\section{References}

1. Banhart J. Manufacturing routes for metallic foams. The Journal of The Minerals, Metals \& Materials Society (TMS). 2000;52(12):22-27.
2. Gupta N, Rohatgi PK. Metal Matrix Syntactic Foams: Processing, Microstructure, Properties and Applications; Book DEStech Publications Inc; 2014. 370 p.

3. Luong DD, Shunmugasamy VC, Gupta N, et al. Quasi-static and high strain rates compressive response of iron and Invar matrix syntactic foams, Materials \& Design. 2015;66:516-531.

4. Metals Handbook. Properties and Selection: Nonferrous Alloys and Special-Purpose Materials. 10th ed. With the second printing; 1992;2.

5. Manonukul A, Muenya N, Léaux F, et al. Effects of replacing metal powder with powder space holder on metal foam produced by metal injection moulding. J Materials Process Technol. 2010;210:529-535.

6. Santa Maria JA, Schultz BF, Ferguson JB, et al. $\mathrm{Al}_{-} \mathrm{Al}_{2} \mathrm{O}_{3}$ syntactic foams - Part I: Effect of matrix strength and hollow sphere size on the quasi-static properties of $\mathrm{Al}-\mathrm{A} 206 / \mathrm{Al}_{2} \mathrm{O}_{3}$ syntactic foams. Mater Science Eng A. 2013;582:415-422.

7. Ferguson JB, Santa Maria JA, Schultz BF, et al. $\mathrm{Al}_{-} \mathrm{Al}_{2} \mathrm{O}_{3}$ syntactic foams-Part II: Predicting mechanical properties of metal matrix syntactic foams reinforced with ceramic spheres. Mater Science Eng A. 2013;582:423-432.

8. Orbulov IN. Compressive properties of aluminium matrix syntactic foams. Materials Science Eng A. 2012;555:52-56.

9. Szlancsik A. Katona B, Bobor K, et al. Compressive behaviour of aluminium matrix syntactic foams reinforced by iron hollow spheres. Materials \& Design. 2015;83:230-237.

10. Orbulov IN, Szlancsik A. On the Mechanical Properties of Aluminum Matrix Syntactic Foams. Adv Engineering Materials. 2018;20:1-12.

11. ASTM Standard E384. Standard Test Method for Knoop and Vickers Hardness of Materials. ASTM; 2011. 